\title{
The management of a dissertation
}

\author{
B. Urban Lombard \\ The Premier Group Ltd.
}

Paper read at the Teachers' Training Programme for South African Universities, University of Pretoria, $9-11$ July 1980

\begin{abstract}
A doctoral thesis is generally speaking the first major and large project a student undertakes. In many instances the manner in which he or she goes about it is very unstructured and often very unorganized. The author describes a systematic approach in managing the activities necessary for the completion of a doctoral thesis.
\end{abstract}

S. Afr. J. Bus. Mgmt. 1981, 12: 26-32

'n Doktorale proefskrif is in die algemeen gesproke die eerste groot projek wat 'n student onderneem. In bale gevalle is die wyse waarop sy of hy dit aanpak baie ongestruktureerd en dikwels ongeorganiseerd. Die skrywer beskryf 'n gesistematiseerde benadering in die bestuur van aktiwiteite wat nodig is vir die voltooiing van ' $n$ doktorale proefskrif.

S.-Afr. Tydskr. Bedryfsl. 1981, 12: 26-32

\footnotetext{
'All men seek one goal: success or happiness. The only way to achieve true success is to express yourself completely in service to society.

First, have a definite, clear, practical ideal - a goal, an objective.

Second, have the necessary means to achieve your ends - wisdom, money, materials and method.

Third, adjust your means to that end.'
}

Aristotle (384 - 322 B.C.)

It appears from discussions with supervisors that most students do not manage their respective projects in the same way and to the extent they have studied their particular field of interest. In our case, the discipline of business economics, that is, the study of the enterprise as the empirical object with the economic principle as the identifying object is the subject matter. In general, we are therefore concerned with the management of an enterprise's resources with the aim to obtain the most favourable ratio between the output (objectives) and input (resources) factors.

This calls for the traditional functions of management namely, planning, organizing, co-ordinating, control and motivating. However, it seems that the students studying management are the worst culprits, since their degree achievement results are reflected in rather poor rates of completion and in particular, long extended time schedules.

The objective of this paper is to outline an approach (systems framework) and methodology (managing by objectives) for a student which he can use in managing the completion of his/her doctoral thesis. This approach emphasizes the early identification of work stages, since students appear to have the most difficulty during this period. This paper will also attempt to outline suggestions for narrowing down subject topics, selecting among alternative levels of investigation, preparing a research proposal and time schedule. A recommendation is also formulated for the introduction of a research methology course for all postgraduate students in the applied disciplines.

\section{The need for a management system}

The following two statements form the framework of our further discussion.

- Structure conditions and controls human behaviour.

- The responsibility for the management and execution of a dissertation is that of the student. 
The underlying philosophy for this systems approach is reflected in the above two propositions. The first premise implies the application of structural elements to the thesis project by means of topic and decision - level analyses, research proposal documents, research plans, time and cost schedules etc. It is believed and argued that these structural elements will and can significantly improve the student's performance and rate of completion.

Not only will it eliminate unnecessary frustration and conflict between supervisor and student, it will also clarify in the student's own mind what he/she wants to do, how, when, where and in what time and cost frame. The detailed research proposal also serves to define and outline the boundaries of the project. This is an all important facet, because close to one-third of all doctoral candidates in the USA who have completed all their programme requirements, except the dissertation, do not even complete it, or take extensive longer periods to complete their thesises.

Some other problems the student and supervisor are faced with are in defining topics, reaching agreement on the scope and methodology of the study and setting a mutually agreeable timetable. As a result, a student who does not adopt an approach of this nature finds himself in an unstructured situation with a high level of uncertainty as to his/her ability to success and an ever present elusive completion date.

The obvious result of if and when he completes his research project, the experiences he had encountered may have been sufficiently traumatic to greatly reduce his desire for future scholarly research. What should have been a learning experience during which time the candidate should have demonstrated his ability to do independent research may now actually result in the candidate losing faith in his competence and ability as a researcher.

Much of the above difficulties can be traced to the fact that students do not know how to manage a research project. Although they may have studied much about their subject topic, discipline and hopefully some research methodology, they are unlikely to have ever been instructed in the management of a dissertation. It is quite clear that the South African university programmes offer no instruction or learning experiences that will adequately prepare students for it. As a result how can supervisors, departments or faculties expect students not to misallocate their efforts and resources, delay preparing a detailed proposal or make unrealistic time estimates?

The fundamental principle involved here is that if the supervisor does not lay down or define some of the structural elements e.g. calling for a detailed research proposal, time and cost schedule, how can he/she expect the student to perform in a specific or appropriate manner?

The commitment of a student to achieve a doctorate degree will probably always be a major undertaking which has certain and definite risks as to completion and acceptance. However, the writer believes that these risks can be substantially reduced and the probabilities of successful and timely completion can be greatly increased if the student and supervisor adopt a systematic approach to the management of a thesis project.

\section{The objectives of a doctoral dissertation}

Although we all may have different ideas as to what objectives a doctoral dissertation ought to have, I trust that the following will find some uniformity among academici.

The general requirement for a doctoral dissertation in an applied field or discipline appears to aim at demonstrating the competence of the candidate to:

- do independent research

- make an original contribution ${ }^{1, p p 9-11}$ to the field of scientific knowledge in the particular discipline or subject

- convert the recommendations into policy implications or directives at various levels eg state, industry, company or individual

- write a scientific research report (dissertation)

- compile and extract from the dissertation the essential data to write a research article

- increase his marketability as a doctoral workseeker in the labour market. ${ }^{2,}$ pp $185-197$

\section{Sources of potential topics}

Davis. pp 8-9 identifies the following sources from which research topics can be generated:

- Current events as discussed in popular journals and later recognised in scholarly or scientific journals.

- Future research suggestions from other thesises.

- Suggested topics for research from authorities in the field.

- Need identification from practitioners in the field.

- Generally accepted statements but unproved premises or assertions.

- Unproved or partially proved propositions by an authority in the field.

- Different approaches or new developed theories for testing important results.

\section{Narrowing the scope of the study}

To assist the student in narrowing down his scope of the study, Fig. 1 attempts to identify the major classifications and levels of investigation. It is of utmost importance to the student to identify and describe quite clearly the categories or levels of investigation and their between and within relationships he/she intends to analyse. A clear understanding and definition of the scope will automatically eliminate many associated methodological problems.

\section{Research proposal outline}

The following outline constitutes a basic framework for a student to think through his/her research project. This structural element serves as the essential tool for the supervisor to monitor the student's ability in managing his research project.

A basic understanding of this document leads to a formal agreement between supervisor and student as to what the whole process and contents of the dissertation will be. Once agreed, this mutual agreement can furthermore be qualified in such terms that only the student can add additional elements to the study, but no one can individual- 


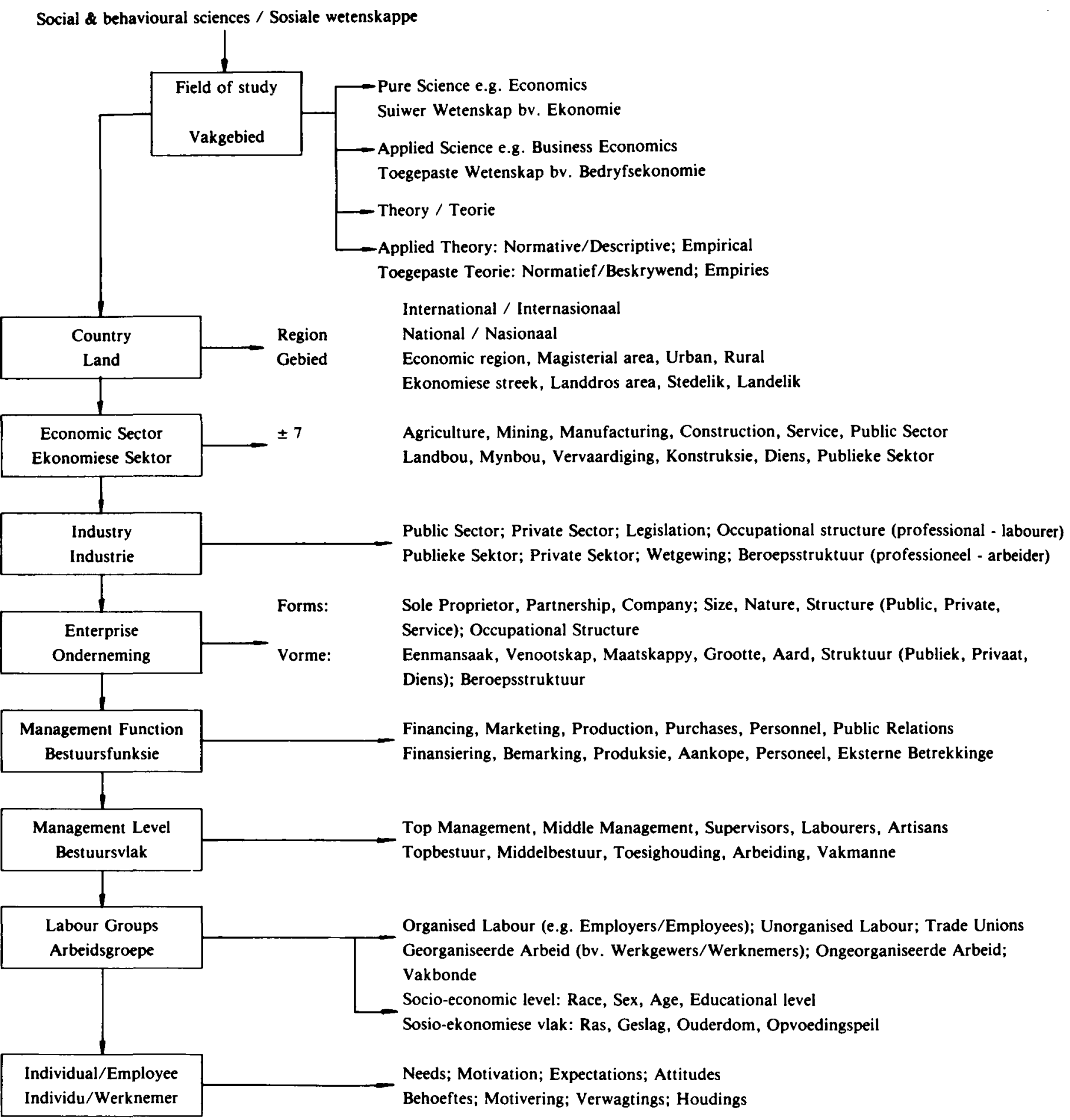

Fig. 1 Decision-making model for research levels / Besluitnemingsmodel vir navorsingsvlakke

ly reduce the items or scope of the study.

The suggested outline, Grazin ${ }^{3}$ contents, also serves to discipline the student's thoughts so that the research process is started off and continued in a sound scientific and scholarly manner. The ultimate ideals the researcher ought to strive for is 'honour', 'wisdom' and 'earnestness'. This proposed research outline attempts to get and keep the student on the 'right' track.

\section{Introduction to the study}

Background comments

Problem motivating this study

Primary difficulty, perplexity, lack of knowledge, etc.
Elements (sub-problems) of primary problem

Purpose of this study

What is to be accomplished

Usefulness of this study to those who may read your report

\section{Previous studies and their findings}

Studies dealing with the same or similar problems Studies with similar subject content

Studies leading to a conceptual base for this research

Theoretical/conceptual basis for this research

(If relevant) Population parameter(s) to be estimated from data 


\section{Relationship(s) expected}

Functional expression(s)

Paradigm(s)

Model(s)

Hypotheses to be tested

Substantive statements

Statistically-testable statements

\section{Mothod}

Overview of research design and method(s) used - the research strategy

Who participated - sampling tactics

How subjects were selected (sampling frame and scheme)

Description of subjects

What used to gather data (instrument) - measurement tactics

Nature of instrument

Definitions of terms used in instrument

Sample questions, scales, other stimuli

How data gathered (how instrument administered)

- process tastics

What subjects did

Where data gathered

When data gathered

How responses coded or scored for analysis

Support for measurement process

Reliability

Validity

\section{Results}

Presentation of data

Tabled data

Tables presented

Verbal reference to tables

Non-tabled data - verbal description

Analyses of data

How analyses conducted

Inferential statistical tests

Non-inferential statistics

Non-statistical analyses

\section{Statement of results}

Important findings e.g., striking differences among control and experimental subjects

Significance of findings (statistical and non-statistical)

\section{Discussion}

Discussion of results (as appropriate)

Relation of results to (support of) hypotheses

Brief overstatement (resume) of results relating to the hypotheses

Support/nonsupport of hypotheses achieved
Implications of results

Contributions to thought (theory or conceptual development)

Contributions to practice (application of findings) to management

Contributions to research methodology

Implications for future research - substance and method

\section{Limitations of study}

Biases from methodological difficulties

Lack of data from design and/or collection difficulties

Low significance/non-significance of results

Inconsistencieds in results (internal and relative to other studies)

Exploratory rather than full research effort

Miscellaneous limitations

\section{Summary and conclusions}

Problem investigated

Methods used

Nature of analyses

Brief statement of results

Implications

\section{Research Proposal Checklist}

The following checklist proposed by Davis ${ }^{1, p .27}$ is not intended to be complete, but it suggests useful questions a student should ask himself as he reviews his proposal.

- Does the proposal have imagination?

- Is the problem stated clearly?

Are the hypotheses clear, unambiguous, and testable?

If no hypotheses, is the objective clearly stated?

Can it be accomplished?

Is the problem too large in scope?

- Is the methodology feasible?

Can data be collected?

How will data be analysed?

Will the analysis allow the accepting or rejecting of the hypotheses?

Is the population to be sampled receptive to investigation?

- What might the results of the analysis look like? A useful technique in clarifying the proposal is to try to sketch the form of the tables or other results from the data analysis. The axes of graphs can be labeled and the probable shape of curves estimated. The expected results from correlation, factor analysis, etc., can be sketched.

- What are the consequences to the thesis of any of the following:

Experiment fails?

Data not obtainable (for each major item of data)?

Small amount of data?

Analysis inconclusive?

Hypotheses rejected? 
SCHEDULE OF CRITICAL REVIEW DATES

\begin{tabular}{|c|c|c|c|c|}
\hline \multicolumn{5}{|l|}{ CRITICAL REVIEW DATES } \\
\hline Review Activity & Review by & Earliest Date & Latest Date & Planned Date \\
\hline Review of final proposal & Committee & & & \\
\hline $\begin{array}{l}\text { Review of methodology or } \\
\text { approach }\end{array}$ & $\begin{array}{l}\text { Advisor } \\
\text { et al. }\end{array}$ & & & \\
\hline $\begin{array}{l}\text { Review of questionnaire and } \\
\text { sampling plan }\end{array}$ & Committee & & & \\
\hline Review of test sample results & Advisor & & & \\
\hline Review of revised sampling & Committee & & & \\
\hline $\begin{array}{l}\text { Review of Chapter } 1 \text { and } 2 \\
\text { etc. }\end{array}$ & Advisor & & & \\
\hline
\end{tabular}

Fig. 2 Schedule of critical review dates (Source: Davis ${ }^{1}$, p.27$^{27}$ )

- Can major research activities be listed?

- Can a time estimate be attached to each major activity?

- Is the thesis trying to accomplish too much?

- If yes to the above, what can be dropped or reduced to make the project more manageable?

- Are there sufficient resources (money, time, computer, administrative assistance etc.) to complete the project?

- Do I as researcher have sufficient skill, competence and motivation to undertake this research project?

Davis ${ }^{1, p .27}$ also suggests a specific schedule to review critical dates. See Fig. 2.

\section{Training needed in the research process and the management of dissertations}

From the above discussion, it has become clear that any dissertation or thesis today, be it a masters or doctorate research study, is in all cases a major project that requires and calls for sound managerial principles to be applied by both the student and supervisor. The student needs to carefully plan, co-ordinate and execute the research steps, while the supervisor fulfills the controlling, monitoring and motivating roles.

To ensure that supervisors, in whatever functional field of business management, business economics, industrial psychology or accounting, are sufficiently equipped to fulfil their supervisory roles with honour, ${ }^{4}$ wisdom ${ }^{5}$ and earnestness, ${ }^{6}$ the following outline of a course in research methodology is proposed for serious consideration and further deliberations.

This course outline only represents some salient issues, as developed by Grazin ${ }^{3}$. The suggested framework therefore is tentative in the sense that topics may be added, deleted or expanded, depending on the needs of the audience.

\section{An outline of a course in the research process}

The philosophy of research - Why we conduct research

Objoctives of resoarch

Research as problem solving - research for application to practice
Management problems

Policy problems

Other problems appropriate for business research

Research as an addition to knowledge - basic research for academia

Theoretical development

Empirical findings (the focus of this course)

What constitutes a substantial contribution

Faculty research

Student research

Levels of contribution

Description

Explanation

Prediction

Control

The conceptual basis of research

Three languages of knowledge

Theory

Conceptual schemes and models

Empiricism

Importance of focussing on functional relationships

Complete process models

Partial models

Hypotheses as a basis for research

Sources of hypotheses

Empirical tests as confirmation of theories and models

Methods of research - How we conduct research

Research design, concepts and paradigms

Four general designs

Experiment

Survey

Observation method

Use of secondary data

Use of previous studies

Research as explanation of variance

Concept of variance

Designing research to explain variance 
Statistical methods as analyses of variance

Chi-square, the method and when applicable

t-test, the method and when applicable

Analysis of variance, the method and when applicable

Regression/correlation, the method and when applicable

\section{Measurement}

Scales and items

Questionnaires and other instruments

Coding for computer analysis

Computer hand analysis: advantages and disadvantages

Analysis and Application

Meaning of test statistics

Interpretation

Significance of results

Use of computer analyses

Useful $v$ non-useful output

Further statistical techniques currently available

A 'handy-jiffy' guide to analytical techniques

Meaning of the results of analyses

Reliability

Validity

Implications for supporting theory

Implications for suggesting further hypotheses

Suggestions for long-range faculty involvement in research

\section{Managing research projects}

Faculty $v$ student projects: similarities and differences

Research proposals

The Granzin 'handy-jiffy' research outline

What constitutes an appropriate proposal for student research

Necessary commitments by the student researcher

Appropriate contributions by the faculty advisor

\section{A PERT chart for research management}

Necessary reviews of the researcher's progress

Important milestones

Need for continual motivation

What constitues completed research

Criteria for judging its adequacy

Formats for the research report

Miscellaneous research aids

Literature searches

A card file for organizing information retrieval and recording

How to write a research report

What to include in a report, what to leave out

Reaching a larger audience with the research results

Strategies for publishing

Writing for publication
Attention is drawn particularly to the section of the outline 'Managing Research Projects' - which adds additional emphasis to our theme of discussion.

Should a department or two at any one university wish to co-ordinate and of fer such a course on a national basis it is also anticipated that a course of this nature, due to its speciality, can probably be open to all other instructors in its formative years, until sufficient competence and skills are instilled in a single department.

This course can be offered for example, by correspondence, calling for a special study school period during the year, where further practical input can be provided by research institutions such as the Human Sciences Research Council's Manpower Division, National Institute for Personnel Research, National Manpower Commission, Department of Statistics, Economic Advisory Council, Economic Development Co-operation and other research orientated institutions or agencies.

The purpose of such an input can ensure that research directors, supervisors, or instructors are introduced to the operational side of managing large public or private research projects.

This course may also highlight the need to introduce a university or specific faculty or department's Style and Format Guide ${ }^{7}$ for the preparation and presentation of thesises and dissertations.

This includes topics such as publication rights; completion and approval of the manuscript by the registrar's office; style in which text and documentation must be prepared; format requirements; duplication; sample pages order and contents; checklist of common errors in format etc.

\section{Conclusion}

A systematic approach, based on managing a research project by objectives may facilitate one student to adopt extremely well to this structured approach while another may be totally frustrated by some of the requirements. It stands to reason that the suggested research proposal outline and methodology course are merely suggestions and should not be used if they are not appropriate. However, it is also common knowledge that sound dissertation management reduces supervisory frustration, student conflict, research costs and completion time.

The overall objective is to ensure that the research process creates a conducive learning situation for the student to want to do further independent research. The main purpose is therefore to build enough structure into the thesis activity that it provides priority over other less important activities. This will facilitate the research project to be carefully planned and executed in good time.

\section{Epllogue}

He who knows and knows that he knows, is a wise man, seek him.

He who knows and knows not that he knows, is asleep, wake him.

He who knows not and knows that he knows not, is a child, help him.

He who knows not and knows not that he knows not, is a fool. shun him. 


\section{References}

1. Davis, G.B.: A Systematic Approach for Managing a Doctoral Thesis. European Institute for Advanced Studies in Management. Working paper 72-38, October 1972.

2. Freeman, R.B.: 'Employment Opportunities in the Doctorate Manpower Market'. Industrial and Labour Relations Review. Vol. 33, No. 2, January 1980.

3. Grazin, K.: 'Handy-Jiffy Research Outline'. Working paper used in a doctorate research methodology course. College of Business. University of Utah, 1979.
4. Honour is defined as . . . personal integrity and excellence of character. It is an enduring quality found in all persons who deserve to lead others.'

5. Wisdom is defined as '. . knowledge tested by experience and tempered by discerning judgement. It abhors prejudice; it insists upon freedom of thought and expression.'

6. Earnesiness is defined as ' . . enthusiasm measured by achieved, disciplined by reason and ennobled by sincerity. It is that dynamic quality which is essential for all great achievement. The earnest person inspires confidence, invites action, and generates progress.'

7. See for example 'A Style and Format Guide for the Preparation and Presentation of Thesis and Dissertations'. Graduate School, The University of Utah, 1975. 